\title{
Türkiye'de Lisansüstü Çalışması Olarak Yapılan İş Sağlığı ve Güvenliği Risk Değerlendirme Uygulamaları Üzerine Bir Araştırma
}

\author{
An Investigation on the Occupational Health and Risk Assessments Performed as \\ Post-Graduate Research in Turkey
}

\author{
Özgür AKKOYUN $\mathbb{B}$, Merve OKUR
}

\begin{abstract}
ÖZET
6331 sayılı İş Sağlığı ve Güvenliği (ISG) kanunu ile birlikte çalışma ortamlarındaki tehlike ve riskleri tahmin edip ortadan kaldırmak, bunun mümkün olmadığı durumlarda kabul edilebilir bir seviyeye getirebilmek için risk değerlendirmesi yapmak veya yaptırmak zorunlu hale gelmiştir. Bu zorunluluk ile birlikte, birçok farklı yöntem ve uygulama gerçekleștirilmiștir. Bu çalışmada, Türkiye'de kullanılan risk değerlendirme yöntemleri araştırma konusu olarak seçilmiştir. Çalışma kapsamında tek tek incelenen yüzlerce risk değerlendirme raporundan elde edilen sonuçlardan bazıları şunlardır; risk değerlendirmesi uygulama sayılarında zaman içinde artış gözlenmiştir, kazaların sık görüldüğü iş alanlarında çalışma sayısı daha fazladır. Risk değerlendirmesi için tek bir yöntemden söz etmek mümkün değildir, aksine birçok farklı yöntem kullanılmaktadır. Her sektör kendisine uygun ve daha iyi yöntemin arayış içindedir.
\end{abstract}

Anahtar Kelimeler: İş Sağlığı Güvenliği, Risk Değerlendirme Yöntemleri, Lisansüstü Çalışmaları, 5x5 L, FineKinney.

\section{ABSTRACT}

Since 2012, when the Occupational Health and Safety law was released (Law No. 6331), it has become compulsory to make or have a risk assessment in order to eliminate or reduce hazards and risks to an acceptable level for all occupational environments in Turkey. Along with this obligation, different methods and many applications have been realized. Some of the results obtained from hundreds of risk assessment reports examined one by one in detail within the scope of the study are as follows; there has been an increase in the number of the risk applications over time, and the number of the risk assessment applications in the industry areas where occupational accidents are common is very higher. It is not possible to talk about a single method for risk assessment, on the contrary, many different methods were used and it was observed that every industry has been trying to find the best risk assessment method that suits itself.

Keywords: Occupational Health and Safety, Risk Assessment Methods, Postgraduate Studies, 5x5 L, FineKinney.

Özgür AKKOYUN | oakkoyun@gmail.com

Dicle Üniversitesi, Mühendislik Fakültesi, Diyarbakır, Türkiye

Dicle University, Faculty of Engineering, Diyarbakır, Turkey

Merve OKUR | okrmrv@gmail.com | Sorumlu Yazar/Corresponding Author Dicle Üniversitesi, isG ABD Yüksek Lisans, Diyarbakır, Türkiye

Dicle University, Department of OHS, Diyarbakır, Turkey 


\section{GİRIŞ}

Dünya Sağlık Örgütü (WHO) ve Uluslararası Çalışma Örgütü (ILO) işs sağlığı ve güvenliğini şu şeklide tanımlamaktadır; Tüm çalışanların bedensel, ruhsal ve toplumsal sağlık ve refahlarının en üst düzeye yükseltilmesi ve bu durumun korunması, iş yeri koşullarının, çevrenin ve üretilen malların meydana getirdiği sağlığa aykırı sonuçların ortadan kaldırılması ve çalışanları yaralanmalara ve kazalara maruz bırakacak risk etmenlerinin önlenmesi, yine çalışanların bedensel ve ruhsal gereksinimlerine uygun bir iş ortamı yaratılmasıdır[1]. Oldukça kapsayıcı ve hemen her şeyi içine alan bu tanımlamanın, tarih içinde yaşanan kazalar ve acı tecrübelerin sonucunda ortaya çıktığı söylenebilir.

Gerçekten de iş sağlı̆̆ı ve güvenliğinin (İSG) günümüzdeki şeklini alması uzun bir tarihsel süreç içerisinde gerçekleşmiştir. Tarih boyunca üretim süreçlerinde yaşanan değişim ve dönüşümler, çalışanlar açısından çok çeşitli sağlık ve güvenlik sorunlarının ortaya çıkmasına neden olmuştur. Yaşanan büyük kazalar, çalışanların çalışma koşullarından kaynaklı sağlık sorunları yaşamaları ve sonunda işverenlere karşı itiraz yükseltmeleri, İSG konusundaki gelişmelerin başlangıcı olmuştur. Ekonomik ve verimli çalışmanın, çalışanların sağlıklı ve huzurlu bir ortamda çalışmasından geçtiğinin anlaşıldığı son yüzyıl ile birlikte, çok çeşitli uzmanlık alanlarında yapılan çalışmalar ve toplum yaşamındaki değişimlere paralel olarak, iş sağlığı ve güvenliği zaman içinde günümüzdeki son şeklini almışıtır.

Türkiye'de çalışma yaşamında iş sağlığı ve güvenliğinin yasal mevzuat içerisinde yer bulması Avrupa ülkelerine kıyasla gecikmiştir. Bunun nedeni Osmanlı İmparatorluğu'nda sanayi devriminin Avrupa'dan çok daha geç gerçekleşmesi hatta tam gerçekleşememesidir. Öyle ki, Avrupa'da 17.yüzyılda atölye ve fabrikalarda üretim yapılırken, Osmanlı İmparatorluğu o yıllarda mesleki etik kuralların, meslek örgütlenmeleri içinde kendi kendine halledildiği; çırağın ustaya emanet edildiği küçük el sanatlarından öteye gidememiştir [2].

Osmanlı İmparatorluğunda işçiyi koruyan ilk mevzuat, aslında amacı kömür üretimini artırmak olan ancak, işçilerin çalışma şartlarına dair birçok hüküm içeren ve 1865 yılında yayınlanan Dilaver Paşa Nizamnamesidir. Ne yazık ki padişah Abdülaziz tarafından onaylanmadığı için hiç uygulanamamıştır[2]. Ardından 1869'da Dilaver Paşa Nizamnamesi yerine çıkarılan ve madenlerde çalışma zorunluluğunu ortadan kaldıran Maadin Nizamnamesi (Madenler yönetmeliği) çıkarılmıştır. Bu yönetmelik İSG açısından ayrıca önem taşımaktadır çünkü Zonguldak kömür madenleri ile ilgili bölgesel bir nizamname olan bu düzenlemede; kaza risklerinin tespit edilmesi, kazaya uğrayan işçilere ödeme yapılması ve madenlerde doktor ve eczane bulundurulması gibi önemli maddeler bulunmaktadır[3]. Bu arada, tarihte birden fazla sayıda maadin nizamnamesi yayımlandığından literatürden takibinin zor olduğunu söylemek gerekir. Osmanlı İmparatorluğunda ilk iş yasası ancak 1877 yılında çıkarılabilmiştir. Mecelle adı verilen bu düzenleme dinsel yönü ağır olan bir yasa olup iş̧̧i sağlığına dair düzenlemeler içermektedir ancak işçi-işveren ilişkilerini kapsayan hükümleri bulunmamaktadır [4].

Cumhuriyet döneminde ise yine Zonguldak madenleri ile ilgili çıkan bir yasa ile günlük çalışma saatleri ilk kez 8 saate indirilmiştir. Bu yasada İSG ile ilgili en önemli düzenleme, İSG kurallarına uymayan madencilerin ruhsatlarının iptal edileceği şeklindeki hükümdür[5]. Ardından 1926 yılında yayımlanan Borçlar kanunu ile işverenler işyerlerindeki iş kazalarından ve meslek hastalıklarından sorumlu tutulmuşlardır. 1930 yılında yürürlüğe giren Belediyeler yasası ile birlikte50 ve daha fazla iş̧̧i çalıştırılan işyerlerinde hekim hizmeti zorunluluğu getirilmiştir[5]. 1936 yılında çıkartılan 3008 sayılı İş Kanunu ile ilk defa 
devletin, işçi işveren ilişkisine müdahale etme durumu söz konusu olmuştur[6]. Yıllar içinde gelişmelere cevap veremeyen İş Kanunu 1967, 1970 ve 1971 yıllarında değiştirilmiştir. 1971 yılındaki değişiklik ile gelen 1475 sayılı yasadaki 73. Madde ile işveren iş̧̧inin sağlık ve güvenliğini sağlamak için üzerine düşen sorumlulukları yerine getirmek, bu husustaki şartları sağlamak ve sağlık ve güvenliği sağlayacak araçları noksansız bulundurmakla yükümlü kılınmıştı[7].

2003 tarihinde yürürlüğe giren İş Kanunu'nun 5. bölümü “İşS Sağlığı ve Güvenliği” başlığını taşımakta idi ve işverenlerin sorumluluklarının sayıldığı ilgili maddesinde işverenlerin mesleki riskler konusunda iş̧̧ileri bilgilendirmek ve eğitim vermek zorunda oldukları da bu bölümde maddeler halinde yazılmıştır. Aynı Kanunda bu konuları düzenlemek için bir yönetmelik düzenleneceğinden de söz edilmektedir[8]. Bu kanunda öngörüldüğü şekilde, üç ay sonra İSG yönetmeliği yayınlanmıştır. Bu yönetmeliğin ilgili maddesinde işverenlerin risk değerlendirmesi (RD) yaptırması gerektiği ifade edilmektedir[9]. 2008 yilında bazı kanunlarda değişiklik yapılması amacıyla çıkarılan bir kanun ile Çalışma Sosyal Güvenlik Bakanlığı (ÇSGB) teşkilat ve görevleri hakkında kanunda bazı değişiklikler yapılmış ve işverenlerin görevleri sayılırken risk analizi ve değerlendirmesi yapmak maddesi de eklenmiştir[10]. Aynı kanunda bu değerlendirmenin nasıl yapılacağını yine çıkarılacak yönetmeliklerin belirleyeceğine vurgu yapılmışır.

Tarih içindeki bu kadar gelişmeye rağmen, 2012 yılına kadar Türkiye'de İSG konusu, başka kanunların içinde alt başılı olarak kalmış, 2012 yılında ise başlı başına bir kanun olan 6331 sayılı İş Sağlığı ve Güvenliği Kanunu yayımlanarak yürürlüğe girmiştir. Bu kanunun geçici maddeleri yukarıda sözü edilen 2003 tarihli İSG yönetmeliğini yürürlükten kaldırmıştır[11]. İSG kanunu risk derlendirmesini "İşyerinde var olan ya da dişarıdan gelebilecek tehlikelerin belirlenmesi, bu tehlikelerin riske dönüşmesine yol açan faktörler ile tehlikelerden kaynaklanan risklerin analiz edilerek derecelendirilmesi ve kontrol tedbirlerinin kararlaştırılması amacıyla yapılması gerekli çalışmalar" şeklinde tanımlamışıı[12]. İSG kanununun hemen ardından sadece RD ile ilgili bir yönetmelik yayımlanmıştır[13]. Bu yönetmelikte tehlikelerin tanımlanması, risklerin belirlenmesi ve analizi ve risk kontrol adımları gibi bölümler bulunmaktadır. Ancak bu yönetmelikte, risk değerlendirmesinin hangi yöntem kullanılarak yapılacağı hakkında bir bilgi verilmemiştir.

Geçen zaman içerisinde, yukarıda sözü edilen İSG kanunu ve ilişkili mevzuatın da etkisi ile iş yerleri iş sağlığı ve güvenliği açısından RD çalışmalarına başlamışlardır. Mevzuatta bir yöntem tercihi ifadesi olmadığı için, eski mevzuatların uygulamalarından dolayı o zamanlar için en bilinen İSG yönetim sistemi ve standardı olan OHSAS (Occupational Health and Safety Assessment Systems) içerisindeki RD yöntemleri tercih edilmiştir. Böylece, aslında Amerikan ordusunun askeri standardı MIL-STD-882$\mathrm{D}$ olarak da bilinen ve sistem güvenlik program gereksinimini karşılamak maksadıyla geliştirilen $5 \times 5$ matris yöntemi, kolay anlaşılması ve kolay uygulanması nedeniyle yaygın bir kullanım alanı bulmuştur [14].

İSG kanununun yayımından itibaren geçen zaman içerisinde, kanundaki işyerlerinin RD yapmaları gerektiğine dair zorunluluk nedeniyle $5 \times 5$ matris yöntemi ve başka yöntemler yaygın olarak hemen her işletmede ve işkolunda kullanılmaya başlanmış ve farklı RD uygulamaları ortaya çımışır. Başlangıçta birbirine çok benzeyen neredeyse aynı yöntemin kullanıldığı RD raporlarının yanı sıra, günümüzde özellikle kurumsal firmaların hazırlattıkları çok ciddi $\mathrm{RD}$ uygulamalarına rastlamak mümkündür.

Konu ile yakın ilgili olanlar, söz konusu RD uygulama- 
larının niteliğini, olumlu olumsuz yanlarını ve bu özelliklerinin zaman içindeki değişimini birkaç cümle ile ifade edebilmektedirler ancak müspet ya da menfi düşüncelerini dayandırabilecekleri ampirik bir çalışma literatürde bulunmamaktadır. Literatürdeki bir çalışmada iş sağlığı ve güvenliği ile ilgili 1585 teze ulaşıldığı ifade edilmiş, ancak bu çalışmada risk değerlendirmesi konusuna yer verilmediği, sadece iş sağlı̆ğ güvenliği konusunda yapılan tüm tezlerin konularına göre dağılımının yapıldığı görülmüştür [15]. Bir başka çalışmada ise [16] yine sadece çalışma konularına göre bir indeksleme yapılmış risk değerlendirme yöntemlerine yer verilmemiştir. Literatürde risk değerlendirme yöntemlerinden söz eden bir çalışmaya rastlanılmamıştır.

$\mathrm{Bu}$ çalışmanın amacı literatürdeki bu boşluğu doldurmaya çalışmaktır.

\section{YÖNTEM}

Bu çalışmada Türkiye'de kullanılan risk değerlendirme yöntemleri araştırma konusu olarak seçilmiştir. Yapılan ön çalışmadan [17] elde edilen sonuçlar göstermiştir ki RD uygulamaları günümüzde genellikle, bu değerlendirmeyi yapmak zorunda olan şirketlerin profesyonel ilişki kurdukları İSG uzmanları ya da bu uzmanları istihdam eden İSG hizmeti veren firmalar aracılığıyla yapıldığı için üçüncü kişiler ile paylaşılmamaktadır. İnternette erişilebilen RD örneklerinin ise; kimler tarafından hangi yöntem kullanılarak nasıl uygulandıkları konusunda bilgi kirliliği gözlendiği için, birbirlerine çok benzeyen ve çok sayıda internet kaynağında farklı isimlerle aynı anda paylaşılan bu raporların bilimsel bir çalışmada veri olarak kabul edilemeyecekleri kanaatine varılmıştır.

$\mathrm{Bu}$ nedenlerden dolayı, üniversitelerde bağlı farklı enstitülerde en az lisans derecesine sahip araştırmacılar tarafından hazırlanan ve bilimsel jüriler tarafından değerlendirilerek kabul edilen lisansüstü çalışmalar veri olarak alınmıştır.
$\mathrm{Bu}$ amaçla, erişime açık tüm lisansüstü tezler taranarak İSG -RD konusunda yapılmış 371 lisansüstü çalışması bulunmuş ve her biri incelenmiştir. Yapılan incelemeler sonucunda elde edilen veriler burada sunulmuştur.

\section{YAPILAN ÇALIŞMALAR VE ELDE EDİLEN BİLGİLER}

Türkiye’de iş sağlığı güvenliği ve risk değerlendirme konularında yapılmış lisansüstü çalışmalarına ulaşmak için Yükseköğretim Kurulunun (YÖK) internet sitesindeki bağlantıdan erişilen Ulusal Tez merkezi kullanılmıştır [18]. Tez merkezinde erişime açılmış olan tezler arasında İSG ve/ veya $\mathrm{RD}$ ile ilişkili kelime taraması ile yapılan aramalar ile 371 adet tez çalışmasına ulaşılmış ve tümü indirilerek incelenmiştir.

İndirilen lisansüstü tez çalışmaları; kullanılan dil, yapılan üniversite, enstitü vb. gibi dokuz farklı kategoride sınıflandırılmış ve aşağıdaki verilere ulaşılmıştır;

\section{A. Verilerin Niteliği}

Genel Tez taraması sırasında farklı anahtar kelimeleri kullanılmış ve bir şekilde İSG ile ilişkili olan çalışmalar değerlendirmeye alınmıştır. Sürekli yeni tezlerin eklendiği sistemde son tarama Aralık 2020 tarihinde gerçekleştirilmiş olup sonraki tarihlerde YÖK tez sistemine eklenen lisansüstü tezler ve araştırmanın yapıldığı tarihlerde çeşitli sebeplerle YÖK tez merkezinde erişime kapalı olan tezler, bu çalışma kapsamının dışındadır. Buna göre 371 adet teze ulaşılmıştır.

\section{B. Yıllara Göre Dağılım}

İncelemesi yapılan tezlerin en eskisi Eylül 2002 tarihini, en yenisi Eylül 2020 tarihini taşımaktadır. 2002 yılında sadece bir adet tez yazılmış iken 2019 yılında bu sayı 101'e ulaşmıştır. 2012 yılına kadar yılda ortalama 3.5 adet tez yazılmış iken 2012 yılın sonra 2020 yılına kadar geçen 
zaman diliminde yıllık ortalama tez sayısı 41'e yükselmektedir. 2020 yılında ise yazılan tez sayısı 46'ya düşmektedir. Yıllara göre yapılan tez sayıları ile ilgili grafik Şekil1'de verilmiştir.

Şekil 1: Yıllara Göre Yapılan Tez Sayıları.

\section{Yıllara Göre Yapılan Tez Sayıları}

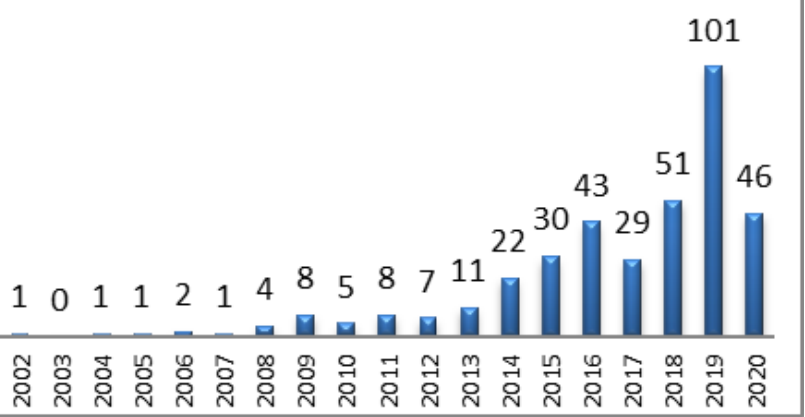

\section{Kullanılan Dil}

Lisansüstü tezlerin yazılmasında ağırlıklı olarak şekil 2.'de de görüldügüü üzere Türkçe dili tercih edilmiş, sadece \%5.4 gibi az bir oranında ise İngilizce kullanılmıştır. İngilizce yazılan tezlerin tamamı eğitim dili İngilizce olan üniversitelerde yazılan tezlerdir. İngilizce yazılan 20 adet tezin 11 tanesi Orta Doğu Teknik Üniversitesi (ODTÜ), 2 tanesi Dokuz Eylül Üniversitesi (DEÜ), 1'er tanesi de İstanbul, Bahçeşehir, Ege, Okan, Gaziantep, Fatih ve Marmara Üniversitelerinde yapılmışlardır.

Şekil 2: Tezlerde Kullanılan Dil

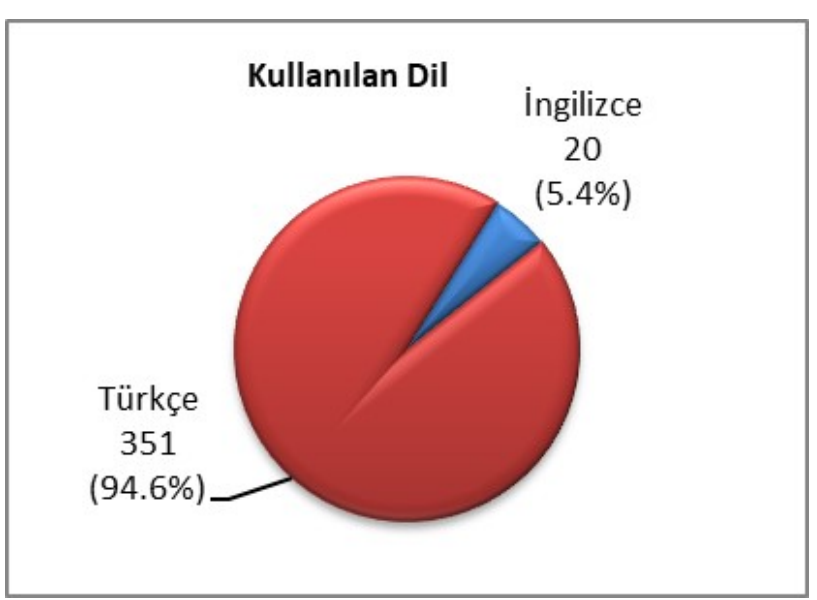

\section{Lisansüstü Çalışmalarının Türü}

89 üniversitede İSG tez konusu olarak seçilmiştir. İncelemesi yapılan bu 371 lisansüstü çalışmasının 333 tanesi gibi çok önemli bir bölümünün yüksek lisans tezi olduğu, bir bölümünün doktora tezi olduğu sadece 5 tanesinin de tıpta uzmanlık tezi olduğu görülmektedir. Lisansüstü çalışma türlerinin dağılımı Şekil 3.'te gösterilmiştir.

Şekil 3: Lisansüstü Tez Çalışması Türü

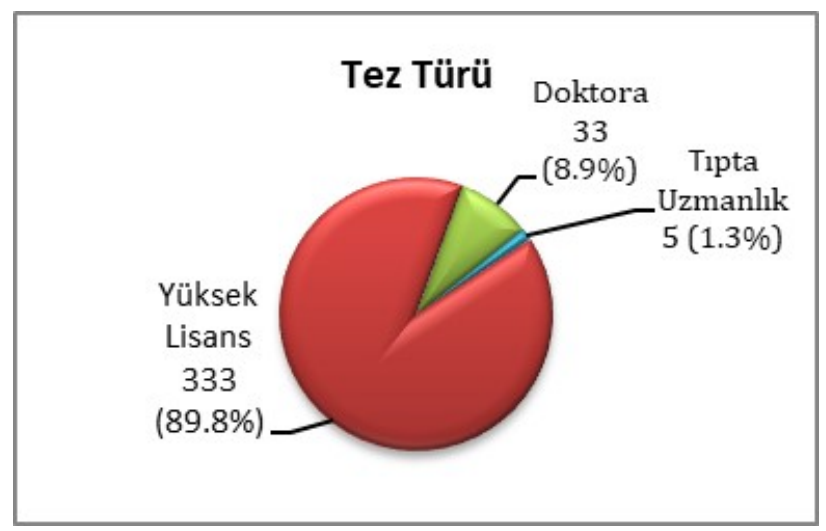

\section{E. Üniversiteler}

Türkiye'de 2021 tarihi itibari ile 200'den fazla üniversite bulunmaktadır. Yapılan bu çalışmada, lisansüstü tez konusu olarak İSG ve/veya RD konularını seçen 89 farklı üniversite tespit edilmiştir. Çukurova, Gazi, Dokuz Eylül, Yeni Yüzyıl, İstanbul Aydın, Üsküdar, ODTÜ, Çanakkale ve İTÜ'deher birinde 10 ve üzeri sayıda olmak üzere 141 tez çalışması yapılırken, kalan 231 tezin 80 farklı üniversitede 10'dan az sayılarda dağıldığı gözlenmiştir.

Tablo 1: Lisansüstü Çalışmaların Üniversitelere Dağılımı

\begin{tabular}{lc}
\hline Üniversite Adı & Tez Sayısı \\
\hline Çukurova Üniversitesi & 25 \\
Gazi Üniversitesi & 19 \\
DEÜ Üniversitesi & 18 \\
İstanbul Aydın Üniversitesi & 17 \\
Yeni Yüzyıl Üniversitesi & 17 \\
Üsküdar Üniversitesi & 13 \\
Çanakkale 18 Mart Ü. & 11 \\
ODTU & 11 \\
iTÜ & 10 \\
Diğerleri (<10 lisans üstü çalışma) & 231 \\
\hline Toplam & 371 \\
\hline
\end{tabular}


Lisansüstü çalışmaların üniversitelere göre dağılımı Tablo 1.'de gösterilmiştir.

\section{F. Enstitü Türleri}

Üniversitelerde lisans çalışmaları fakülte ve yüksek okullarda, lisansüstü çalışmaları ise enstitülerde yapılmaktadır. Türkiye'deki çalışma kapsamında incelenen çalışmaların yapıldığı 89 farklı üniversitedeki lisansüstü tez çalışmalarının enstitülere göre dağılımı şöyledir; 277 adet tez fen bilimleri enstitüsüne, 51 adet tez sağlık bilimleri enstitüsüne, 42 adet tez sosyal bilimler ve 1 adet tez de eğitim bilimleri enstitüsüne bağlı olarak tamamlanmıştır. Bazı üniversitelerde fen bilimleri enstitüsü adının lisansüstü eğitim enstitüsü olarak kullanıldığı görülmüştür. Çok azı ise fen bilimleri enstitüsü yerine mühendislik ve fen bilimleri enstitüsü adı altında faaliyet göstermektedir. Bu tür isim değişiklikleri dikkate alınıp yapıldıkları lisans bölümleri dikkate alınarak değerlendirme yapılmış ve bu enstitüler fen bilimleri enstitüsü olarak değerlendirilmişlerdir. Lisansüstü çalışmaların yapıldığı enstitü yüzdeleri Şekil 4.'te gösterilmiştir.

Şekil 4: Lisansüstü Çalışmaların Yapıldığı Enstitüler

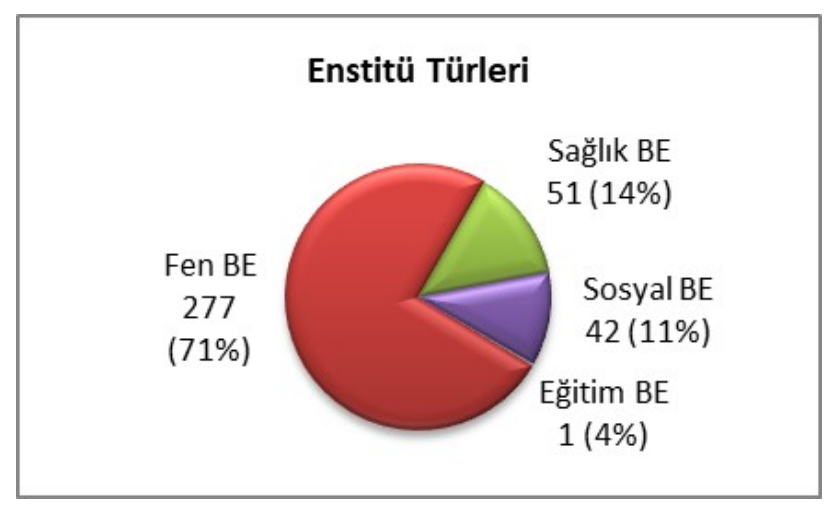

\section{G. Anabilim Dalları}

Üniversitelerde farklı fakültelerin değişik bölümlerinden mezun olan lisans mezunları, lisansüstü çalışmalarını enstitülere bağlı olarak gerçekleştirirken fakültelere bağlı bölümler enstitü açısından anabilim dalı (ABD) olarak değerlendirilmektedir. İSG’nin disiplinler arası özelliğinden dolayı, birçok farklı ABD ile ilişkisi bulunmakta ve lisansüstü çalışmasına konu olabilmektedir. Çalışma kapsamında incelenen tezlerde İSG ve RD konularını ele alan 43 farklı anabilim dalı tespit edilmiştir.

$\mathrm{Bu}$ anabilim dallarının başta iş sağlığı anabilim dalı olmak üzere, Maden Mühendisliği, Endüstri Mühendisliği, İşletme, Çevre Mühendisliği, Orman Endüstri Mühendisliği, İnşaat, Kimya ABD gibi birçok anabilim dallarında yapıldığı görülmüştür. Bu anabilim dallarının bazılarında

Tablo 2. Lisansüstü Çalışmaların Anabilim Dallarına Göre Dağılımı

\begin{tabular}{|c|c|}
\hline Anabilim Dalı & Tez Sayısı \\
\hline İş Sağlığı Güvenliği & 157 \\
\hline Maden Müh. & 55 \\
\hline Endüstri Müh. & 26 \\
\hline İşletme & 22 \\
\hline Çevre Müh. & 14 \\
\hline Orman Endüstri Müh. & 13 \\
\hline İnşaat Müh. & 10 \\
\hline Kimya Müh. & 8 \\
\hline Halk Sağlığı & 7 \\
\hline Makine Müh. & 7 \\
\hline Çalışma Ekonomisi & 6 \\
\hline Ağaç İşleri Endüstri Müh. & 3 \\
\hline Hukuk & 3 \\
\hline Kazaların Çevresel ve Teknik Araştırması & 3 \\
\hline Mimarlık & 3 \\
\hline Sağlık Yönetimi & 3 \\
\hline Geomatik Müh. & 2 \\
\hline Malzeme Bilimi ve Müh. & 2 \\
\hline Mühendislik Yönetimi & 2 \\
\hline Teknik Eğitim & 2 \\
\hline Toplam Kalite & 2 \\
\hline Diğerleri (21 adet) & 1 \\
\hline Toplam & 371 \\
\hline
\end{tabular}


İSG ve RD ilişkili konular sadece bir veya iki tez çalş̧masında konu edilmişken, İSG anabilim dalında 157 adet tez, Maden Mühendisliği Anabilim dalında 56 tez çalışmasının, Endüstri Mühendisliği Anabilim dalında 26 tez çalışmasının yapıldığı görülmüştür. Anabilim dallarına göre yapılan tez dağılımları Tablo 2.'de verilmiştir.

\section{H. Risk Değerlendirme Yöntemleri}

Çalışma kapsamında incelenen 371 adet tez çalışmasının 60 tanesinde risk değerlendirme uygulaması bulunmamaktadır. Geriye kalan çalışmaların 189 tanesinde bir adet risk değerlendirme yöntemi kullanılarak bir işyerinde uygulama yapılmış, 91 tanesinde birden fazla sayıda risk değerlendirme uygulaması yapılmış ve kalan 31 tanesinde ise çalışmanın kendisinde yeni bir risk değerlendirme yöntemi önerilmiştir.

Risk Değerlendirme çalışma dağglımları Şekil 5.'te gösterilmiştir.

Şekil 5: Risk Değerlendirme Çalışmalarının Dağı̆lımı.

\begin{tabular}{|c|c|} 
Uygulama \\
Yok, 60 \\
$16 \%$
\end{tabular}

\section{Uygulama İçermeyen Tez Çalışmalarının Konusu}

Araştırma kapsamında değerlendirmeye alınan lisansüstü çalışmalarının bir bölümü, İSG ve/veya RD konusunu bir biçimde ele almakla birlikte, bir RD uygulaması içermemektedir. Bu çalışmaların bir bölümü Şekil 6.'da gösterildiği üzere işyerlerinde yapılan anketler, bir bölümü geç- miş çalışmalar ile ilgili bir tür literatür taraması, bazıları istatistik analizler içeren çalışmalar birkaç tanesi ise İSG’nin sadece gürültü ya da titreşim riskleri gibi alt konularını içeren çalışmalardır. Bu çalışmaların toplam sayısı 60 olup toplam tezler içindeki oranı $\% 16$ 'dır.

Şekil 6: Risk Analiz İçermeyen Çalışmaların İçeriği

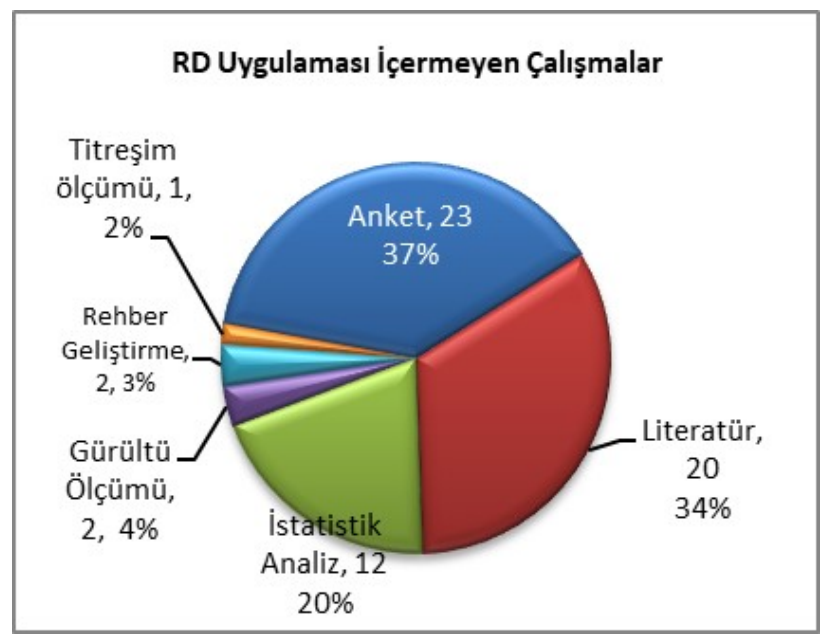

J. Tek Yöntem ile RD Uygulaması Yapılan Çalışmalar

En az bir risk değerlendirme yöntemi kullanılarak uygulama yapılan lisansüstü çalışmaları incelendiğinde en sık kullanılan yöntemin Çizelge 3.' te gösterildiği üzere $5 \times 5$ L matris yöntemi adı verilen yöntem olduğu anlaşılmıştır. 84 tezde kullanılan 5x5 L matrisi yöntemini, 45 kez kullanılan Fine-Kinney yöntemi izlemektedir. Hata türleri ve etkileri analizi (HTEA) $21 \mathrm{kez}, 3 \mathrm{~T}$ yöntemi 9 kez, OHSAS 7 kez, Kinney 4, Hata ağacı analizi (FTA) 3 kez, Elmeri, HAZOP ve REBA yöntemleri 2'şer kez uygulanmışlardır. On adet tezde ise farklı yöntemler birer kez kullanılmışlardır.

\section{K. Farklı RD Yöntemlerini Karşılaştıran Çalışmalar}

Çalışma kapsamında incelenen 91 adet çalışma (her dört lisansüstü çalışmasının bir tanesi), birden fazla risk değerlendirme yöntemini bir işyerinde uygulayarak yöntemler arasında karşlaş̧ırma yapmayı amaçlamışıı. Bu karşılaştırma çalışmalarında en sık karş̧laştırılan iki yöntem 
Tablo 3: Tek Yöntem Olarak Uygulanan Risk Değerlendirme Yöntemleri

\begin{tabular}{lc}
\hline Yöntem Adı & Adet \\
\hline 5x5 L Matris & 84 \\
Fine-Kinney & 45 \\
HTEA (Hata Türleri ve Etkileri Analizi) & 21 \\
3T & 9 \\
OHSAS & 7 \\
Kinney & 4 \\
FTA (Hata Ağacı Analizi) & 3 \\
Elmeri & 2 \\
HAZOP (Tehlike ve İşletilebilirlik) & 2 \\
REBA (Ergonomik Riskler) & 2 \\
AHP (Analitik Hiyerarşi Prosesi) & 1 \\
LMM (Anahtar Özellik Yöntemi) & 1 \\
Bayes Ağı & 1 \\
Bulanık TOPSis & 1 \\
ESM (Çevresel Gerilim Modeli) & 1 \\
Kontrol Listesi & 1 \\
Olursa Ne Olur & 1 \\
Papyon Analizi & 1 \\
PHA (Ön Tehlike Analizi) & 1 \\
RMD (Riske Maruz Değer Yöntemi) & 1 \\
\hline Toplam & 1 \\
\hline & 1 \\
\hline
\end{tabular}

5x5 L matris yöntemi ile Fine-Kinney yöntemleridir. Çalışmaların bazılarında iki yöntem uygulanarak karşılaştırma yapılırken bazı çalışmalarda bu sayı beş farklı yönteme çıkmaktadır. Bu yöntemler Tablo 4 'te verilmiştir.

\section{RD Yöntemlerinin Uygulandıkları Sektörler}

Çalışma kapsamında incelenen lisansüstü çalışmalarındaki iş sağlığı güvenliği ve risk değerlendirme çalışmalarının, çok farklı mesleklerdeki birbirinden değişik iş kollarına uygulandıkları görülmüştür(Çizelge5). Çalışma ile 80 farklı iş kolu tespit edilmiştir, Bunlardan 27 tanesinde 5 ve daha fazla RD uygulaması tespit edilirken, kalan 53 tanesinde 4 ve daha az sayıda RD uygulaması içeren lisansüstü çalışma yapıldığı tespit edilmiştir.
Tablo 4. Birden Fazla Uygulanan Risk Değerlendirme Yöntemleri

\begin{tabular}{|c|c|}
\hline Uygulanan Yöntemler & Adet \\
\hline $5 \times 5$ L, Fine-Kinney & 23 \\
\hline $5 \times 5$ L, Fine-Kinney, HTEA & 5 \\
\hline $5 \times 5$ L, Kontrol Listesi & 5 \\
\hline Fine-Kinney, HTEA & 5 \\
\hline Fine-Kinney - Anket & 3 \\
\hline $5 \times 5 \mathrm{~L}, 3 \mathrm{~T}$ & 2 \\
\hline $5 \times 5 \mathrm{~L}$, Anket & 2 \\
\hline $5 \times 5 \mathrm{~L}, \mathrm{HAZOP}$ & 2 \\
\hline Fine-Kinney, 3T & 2 \\
\hline $5 \times 5$ L, Fine-Kinney, 3T, Kontrol Listesi & 1 \\
\hline $5 \times 5$ L, Fine-Kinney, AHP, HTEA & 1 \\
\hline $5 \times 5$ L, Fine-Kinney, Anket & 1 \\
\hline $5 \times 5$ L, Fine-Kinney, HTEA, HAZOP & 1 \\
\hline $5 \times 5$ L, Fine-Kinney, Kontrol Listesi & 1 \\
\hline $5 \times 5$ L, Fine-Kinney, Kontrol Listesi, HAZOP & 1 \\
\hline $5 \times 5 \mathrm{~L}, \mathrm{AHP}$ & 1 \\
\hline $5 \times 5$ L, Balık Kılçı̆̆ı, ETA, HTEA, Kontrol Listesi & 1 \\
\hline $5 \times 5 \mathrm{~L}, \mathrm{FTA}$ & 1 \\
\hline 5x5 L, FTA, Papyon Analizi & 1 \\
\hline $5 \times 5$ L, HTEA & 1 \\
\hline 5x5 L, HTEA, Papyon Analizi, İş Güvenliği Analizi & 1 \\
\hline $5 \times 5 \mathrm{~L}, \mathrm{JRA}$ & 1 \\
\hline $5 \times 5 \mathrm{~L}, \mathrm{PHA}, \mathrm{HRNS}$ & 1 \\
\hline $5 \times 5$ L, Pisagor Bulanık Küme Tabanlı TOPSIS & 1 \\
\hline $5 \times 5$ L, PRA & 1 \\
\hline Fine-Kinney, ETA & 1 \\
\hline Fine-Kinney, HTEA, Anket & 1 \\
\hline Fine-Kinney, TOPSIS ve MAUT & 1 \\
\hline Fine-Kinney, VIKOR Yöntemi & 1 \\
\hline AHP, HTEA & 1 \\
\hline$A H P, I F$ & 1 \\
\hline AHP-Anket & 1 \\
\hline Anket, $10 \times 10$ Matris & 1 \\
\hline Anket, AHP, Bulanık AHP, TOPSIS & 1 \\
\hline Anket-Kontrol Listesi & 1 \\
\hline Anket-REBA & 1 \\
\hline DEMATEL, AAS, TOPSIS & 1 \\
\hline FTA, ETA, Papyon Analizi & 1 \\
\hline GMP, HTEA, Kinney & 1 \\
\hline HAZOP, FTA, ETA & 1 \\
\hline HTEA, FUCOM, KEMIRA-M & 1 \\
\hline Kontrol Listesi, HTEA & 1 \\
\hline Kontrol Listesi, Kinney & 1 \\
\hline OWAS, REBA, RULA & 1 \\
\hline Papyon Analizi, LOPA & 1 \\
\hline PHA Kinney, HTEA & 1 \\
\hline REBA, Anket & 1 \\
\hline REBA, OWAS, QEC, PLIBEL, MANTRA & 1 \\
\hline REBA, RULA VENIOSH & 1 \\
\hline REBA, RULA, QEC & 1 \\
\hline REBA, RULA, Snook & 1 \\
\hline Toplam & 91 \\
\hline
\end{tabular}


$\mathrm{Bu}$ sektörlerin başında, iş kazalarının da en yüksek oranlarda gözlendiği, inşaat ve madencilik sektörleri gelmektedir. Onları; sağlık, tersane işleri, gıda ve metal sektörleri izlemektedir.

\section{SONUÇ VE DEĞERLENDİRMELER}

Bu çalışmada Türkiye'de kullanılan risk değerlendirme yöntemleri araştırma konusu olarak seçilmiş ve ön çalışma ile RD uygulamalarının genellikle, şirketlerin profesyonel ilişki kurdukları İSG uzmanları ya da bu uzmanları istihdam eden İSG hizmeti veren firmalar aracıllğıyla yapıldığı için üçüncü kişiler ile paylaşılmadığı tespit edilmiştir. İnternetteki açık kaynaklardan elde edilen RD örneklerinin ise bir bilimsel çalışmaya konu olacak kadar güven vermedikleri belirlenmiştir. Bu nedenle araştırma konusu olarak İSG-RD konularında yapılan lisansüstü çalısmalar veri olarak seçilmiş ve yaklaşık 400 tez incelenmiştir. Elde edilen sonuçlar aşağıdaki gibidir;

En son aramanın Aralık 2020 tarihinde yapıldığı tez taramasında başlangıçta 410 tez İSG-RD konuları ile ilişkili bulunmuş, ön okumanın ardından sayıları 371'e düşmüştür. Yıllara göre yapılan çalışmalar incelendiğinde ilk çalışmanın 2002 yılında yapıldığı, 2012 yılına kadar önemli bir artış olmadığı, 2013 ve sonrasında ise çalışma sayısında büyük bir artış olduğu görülmektedir. 6331 sayılı İSG yasasının 2012 yılında çıkması bu artışı en önemli sebebi olarak görülmektedir. Çalışma sayısındaki artış devam eğilimi göstermektedir. Şekill'de verilen grafikte 2020 yılındaki düşme yanılıcı olmamalıdır, YÖK sistemine eklenen tezler, yazarları ve danışmanları tarafından çeşitli sebeplerle bir ya da iki yıl sonra kullanıma açılmaktadırlar. Dolayısıyla 2020 yılında yapılan bir taramada, sadece kullanıma açık tezlerin taranması durumunda 2020 yılına ait gerçek çalışma sayılarına ulaşmak mümkün olmayacak, bunun için en az bir yıl beklemek gerekecektir.
1. İncelenen çalışmaların \%95 gibi önemli bir bölümü Türkçe yazılmış, sadece öğretim dili İngilizce olan üniversitelerde yapılan çalışmaların İngilizce yazıldığı görülmüştür. Çalışmalarda ağırılık yüksek lisans (\%89) olsa da İSG yasasının bile sadece 9 yıl önce çıktığı düşünülürse 4-5 yıl süren doktora çalışmalarına yeterli sayıda konu olması için bir süre daha beklememiz gerektiği değerlendirilebilir. Ayrıca, yüksek lisans çalışmalarındaki oransal fazlalığın bir nedeni de, son yıllarda sayıları artan özel üniversitelerde açılan İSG ile işkili anabilim dallarına olan öğrenci ilgisi gösterilebilir. 6331 sayılı kanun ile birlikte yeni yaratılan bir iş kolu olan iş güvenliği uzmanlığı (B) unvanına ulaşmanın görece daha kolay bir yolu, bu alanda yüksek lisans yapmaktır [19]. Bu durumun bir talep artışına neden olduğu ve bazı özel üniversitelerin bu talebi en hızlı şekilde görüp değerlendirdikleri kanaati oluşmuştur.

2. İSG-RD konularında çalışma yapılan 89 farklı üniversite tespit edilmiş olsa da en çok çalışma yapılan üniversiteler listesindeki ilk 6 üniversiteden 3 tanesinin görece yeni kurulan özel üniversiteler olması dikkat çekicidir. Özel üniversitelerin İSG konusuna olan bu ilgisinin nedenlerinden birisi bir önceki maddede açıklanmışır. Ancak, bu amaçla yapılan lisansüstü çalışmaların özellikle bazılarındaki bilimsel kalite ve içerik, başka bir çalıssmanın konusu olabilecek kadar sorunludur.

3. Çalışma kapsamında incelenen lisansüstü tez çalışmalarının enstitülere göre dağılımı şöyledir; 277 adet tez fen bilimleri enstitüsüne, 51 adet tez sağlık bilimleri enstitüsüne, 42 adet tez sosyal bilimler ve 1 adet tez de eğitim bilimleri enstitüsüne bağlı olarak tamamlanmıştır. İş sağlığı güvenliği ile ilgili iş kollarının çoğunluğunun fen ve mühendislik bilimlerinin çalışma alanında olmaS1 nedeniyle çalışmaların çoğunluğunun mühendislik bilimlerinin bağlı olduğu fen bilimleri enstitüsünde 
yapılmış olmaları beklenen bir durumdur. Halk sağlığı ile ilişkilendirilen işs sağlığı güvenliği çalışmaları ise çoğunlukla sağlık bilimleri enstitüsü çatısı alında gerçekleştirilmiştir. İSG’nin toplumun her kesimi tarafından benimsenmesi ve iş kazalarının azaltılması için diğer enstitüler ve bilim dallarının da özellikle sosyal ve eğitim bilimlerinin de bu alanda çalışma yapması gerektiği değerlendirilmiştir. İş kazası literatüründe kaza sebeplerinin en büyügünün 'Tehlikeli davranış' olduğu ifade edilmektedir [20]. Eğitim bilimleri ve sosyal bilimlerde yapılacak çalışmalar ile bu soruna çözümler aranabileceği değerlendirmesi yapılmıştır.

4. İSG'nin disiplinler arası özelliğinden dolayı, birçok farklı ABD ile ilişkisi bulunmakta ve farklı alanlardaki lisansüstü çalışmasına konu olabilmektedir. Çalışma kapsamında 43 farklı anabilim dalında RD uygulaması yapıldığı, Maden Mühendisliği, Endüstri Mühendisliği, İşletme, Çevre Mühendisliği, Orman Endüstri Mühendisliği ve İnşaat dallarının öne çıktığı görülmüştür. İSG kanunu sonrası açılan İSG anabilim dallarında yapılan tezler öne çıksa da genelde iş kazalarının en çok yaşandığı ve çok tehlikeli işler sınıfında yer alan maden, endüstri, inşaat gibi anaların ön plana çıkmasının normal olduğu değerlendirmesi yapılmıştır.

5. İncelenen çalışmalardan büyük bölümünde mevcut risk değerlendirme yöntemleri kullanılmış, bazılarında karşlaştırmalar yapılmış, son dönemlerde ise yeni yöntemler önerilmeye başlandığı görülmüştür. Başlangıçta hemen herkesin kullandığı, basit prosedürlü işlerde rahatlıkla kullanılabilen, doküman ihtiyacının neredeyse olmadığı, orta düzeyde deneyime sahip bir analistin yapabileceği, risk skorunun ihtimal ve zarar derecesinin çarpımından elde edilerek bulunan(Risk Skoru = İhtimal x Zarar Derecesi) [14] 5×5 L matris yönteminden yavaş da olsa vazgeçildiği, yerine 1971 yılında Fine tarafindan Kaliforniya Donanma Silah Merkezi için geliştirilen ve Kinney ve Wiruth tarafindan 1976 yılında revize edilip yayınlanan günümüzde Fine-Kinney yöntemi olarak bilinen, sadece ihtimal ve şiddetin değil frekansın da dikkate alındığı (R=Olasılık x Frekans x Şiddet) [21] Fine-Kinney yönteminin tercih edilmeye başlandığı değerlendirilmiştir. Risk hesaplamasını iki parametre ile yapan $5 \times 5 \mathrm{~L}$ matris yönteminden, hesaplamayı üç parametre ile yapan bir yönteme doğru bir yöneliş olduğu görülmektedir. İşin ilginç tarafi; çok yeni yapılan bir çalışmada [22], risk hesaplamasını dört parametre ile yapan bir yöntem olan HRNS yöntemi $5 \times 5$ L matris yöntemi ve Fine-Kinney yöntemleri ile karşılaştırılmış ve daha fazla parametre ile risk hesaplayan HRNS yönteminin daha avantajlı olduğu sonucuna varılmıştır.

6. Yapılan yöntem karşılaştırması çalışmaları toplam tezlerin 1/4̌ üne ulaşmıştır. Buradan, genel bir yöntem tespit etme çabası olduğu sonucuna varılabilir. En fazla karşılaştırılan yöntem, yine en fazla kullanılan 5x5 L matris yöntemidir ve karşılaştırmaların çoğunda alternatif yöntemin daha iyi olduğu ortaya çıkmıştır. Bunun dışında, yirmiden fazla yöntemin farklı alanlarda uygulandığı gözlenmiştir. Ayrıca kısa da olsa oluşan birikim ve tecrübelere dayanılarak, artık yeni yöntem önerilinin de yapıldığı, bu yöntem önerilerinde yapay zeka, bulanık mantık gibi esnek hesaplama yöntemlerinin kullanılmaya başlandığı da gözlenmiştir.

7. İçerisinde risk değerlendirmesi olmayan ancak, iş kazalarına ve iş sağlığı güvenliğine farklı açılardan bakan, çok değerli bilimsel çalışmaların, çalışanların görüşlerinin alındığı anket çalışmalarının, sorunların sosyal, psikolojik ve yasal boyutlarını ortaya koymaya çalışan önemli çalışmaların da olduğunu ifade etmek gerekir. 
8. Son olarak, risk değerlendirme çalışmaların uygulandığı sektörlerin başında açık ara ile madencilik önde görülmektedir. Madenciliği, inşaat, sağlık, tersane ve gıda sektörleri takip etmektedir. Yaşanan kazalar ve risk seviyesinin yüksek olması, risk değerlendirme yöntemlerinin ve bilimsel çalışmaların bu sektörlere yönelmesine neden olduğu değerlendirmesi yapılmıştır.

Yazar Katkılları: Bu çalışmada yazarların katkıları eşit düzeydedir.

ÇıKar ÇATışması: Bu çalışmada herhangi bir çıkar çatışması yoktur, makale araştırma ve yayın etiğine uygundur.

Finansal Destek: Bu çalışmada herhangi bir kişi, kurum veya kuruluştan finansal destek alınmamıştır.

Етік Коміте Onayı: İnsan örneği veya deneysel çalışma içermediğinden etik kurulu oluru gerekmemiştir.

\section{KAYNAKÇA}

[1] Güvercin, C.,H., (2004). Sosyal Güvenlik Kavramı ve Türkiye'de Sosyal Güvenliğin Tarihçesi. Ankara Üniversitesi Tıp Fakültesi Mecmuası, 57(2), 89-95.

[2] Alper, Y., (1992). Bazı Ülkelerde İşçi Sağlı̆̆ı-İş Güvenliği Uygulamaları ve Türkiye'deki Uygulama İleKarsılaştırılması. Sosyal Siyaset Konferansları Dergisi, 0(37-38), 83-101.

[3] Turan, M., (1981). Madenciliğimizin Tarihsel Gelişimi, https://www.maden.org.tr/resimler/ekler/ b4e2b9376139fa0_ek.pdf , Erişim Tarihi:24.04.2021.

[4] Makal, A., (1997). Osmanlı İmparatorluğunda Çalışma İlişkileri-Türkiye Çalışma ilişkileri Tarihi, İmge Kitabevi, Ankara.

[5] Süzek, S., (1985). İş Güvenliği Hukuku, Savaş Yayınları, Ankara.

[6] Gürbüz, Y., (1998).İş Güvenliğine Genel Bakış. Mühendis ve Makine Dergisi, 224.

[7] Arseven, F., (2004). Yeni İş Güvenliği Kanunu'nun İs Sağlığı ve Güvenliği Yaklaşımı. TİSK İşveren Dergisi, Nisan Sayısı

[8] 4857 Sayılı İş Kanunu, (2003). https:// www.mevzuat.gov.tr/MevzuatMetin/1.5.4857.pdf, Erişim Tarihi: 20.04.2021.
[9] İş Sağllı̆ı ve Güvenliği yönetmeliği, (2012). https:// www.mevzuat.gov.tr/mevzuat?

Mev-

zuatNo=16924\&MevzuatTur=7\&MevzuatTertip=5 , Erişim Tarihi: 24.04.2021.

[10] 5763 Numaralı Kanun, (2008). https:// www.resmigazete.gov.tr/eskiler/2008/05/20080526-

5.htm , Erişim Tarihi: 24.04.2021, ve 3146 Sayılı Çalışma ve Sosyal Güvenlik Bakanlığının Teşkilat ve Görevleri Hakkında Kanun, (2011). https:// www.resmigazete.gov.tr/ eskiler/2011/11/20111102M1-5.htm, Erişim Tarihi: 24.04.2021.

[11] 6331 İş Sağlığı ve Güvenliği Kanunu,(2012). https:// www.mevzuat.gov.tr/MevzuatMetin/1.5.6331.pdf , Erişim Tarihi:20.04.2021.

[12] 6331 İş Sağlığı ve Güvenliği Kanunu geçici $1 \mathrm{md}$, (2012). https://www.mevzuat.gov.tr/ MevzuatMetin/1.5.6331.pdf , Erişim Tarihi: 24.04.2021.

[13] İş Sağlığı Ve Güvenliği Risk Değerlendirmesi Yönetmeliği, (2012), ,https://www.mevzuat.gov.tr/ mevzuat?

Mev-

zuatNo=16925\&MevzuatTur=7\&MevzuatTertip $=5$, Erişim Tarihi: 20.04.2021.

[14] Özkılıç, Ö., İş Sağlığı ve Güvenliğii, Yönetim Sistemleri ve Risk Değerlendirme Metodolojileri, http:// egitim.druz.com.tr/upload/ docs/26042012105841_vAq1THf-6-105841_riskanalizi-ozlem-ozkilic-kitabi.pdf , Erişim Tarihi: 24.04.2021.

[15] Keçeci, Ş., 2020, İş Sağlığı ve Güvenliği Alanında Yazılan Yüksek Lisans ve Doktora Tezlerinin Konularına Göre Dağılımının İncelenmesi, İSG Akademik, Cilt, 2, s. 117-122.

[16] Ulutaşdemir N., Tuna H. \& Ertürk İ. 2019. İş sağllğı ve güvenliği alanında Türkiye'de yapılan lisansüstü tez çalışmalarının incelenmesi. Gümüşhane Üniversitesi Sosyal Bilimler Enstitüsü Elektronik Dergisi, 10 (1), 32-41

[17] Okur, M., (2020). Açık Kaynaklardaki Risk Değerlendirme Raporlarının İstatistiksel Değerlendirilmesi, Dicle Üniversitesi, Sağlık Bilimleri Enstitüsü, Yayınlanmamış Dönem Projesi, Diyarbakır.

[18] https://tez.yok.gov.tr/UlusalTezMerkezi, Erişim Tarihi: 24.04 .2021

[19] İş Güvenliği Uzmanlarının Görev, Yetki, Sorumluluk ve Eğitimleri Hakkında Yönetmelik, (2012). https:// www.mevzuat.gov.tr/mevzuat?Mevzuat $N_{0}=16923 \&$ 
MevzuatTur=7\&MevzuatTertip=5, Erişim Tarihi: 20.04.2021.

[20] Yılmaz, Aİ, (2013). İş Sağlığı ve Güvenliğinde Kaza Zinciri Teorisinin Önemi ile Açı İşletmelerdeki Tehlikeli Hareket ve Tehlikeli Durumlar, Yer altı Kaynakları Dergisi, 2(3), 27-39.

[21] Aker A, Özçelik T.Ö., (2020). Metal Sektöründe 5x5 Matris ve Fine-Kinney Yöntemi ile Risk Değerlendirmesi, Karaelması İş Sağlığı ve Güvenliği Dergisi, 4(1), 65-75.

[22] Ekinci, G., (2020). Bir Yeraltı Maden İşletme Tesisinde İş Sağlığı Ve Güvenliği Uygulamaları Ve Farklı Risk Değerlendirme Yöntemlerinin Karşılaştırılması, Dicle Üniversitesi, Fen Bilimleri Enstitüsü, Yayınlanmamış, Yüksek Lisans Tezi, Diyarbakır. 